\title{
Thanks for the memories ...
}

\section{Geoffrey Schoenbaum ${ }^{1}$ and Thomas A. Stalnaker}

Department of Anatomy and Neurobiology and Department of Psychiatry, School of Medicine, University of Maryland, Baltimore, Maryland 21201, USA

Modern approaches to learning and memory have shown conclusively that memory can be fractionated in complex ways and that this fractionation reflects the operation of "multiple memory systems" (McDonald and White 1993; Bechara et al. 1995). Of course, if there are multiple memory systems operating in parallel, then they must interact. On the face of it, one might expect that such interactions would facilitate more efficient memory and behavior. Indeed, this appears to be true in many cases; for example, the amygdala appears to act to enhance the encoding of hippocampal-dependent memory, an effect that explains the emotional modulation of the strength of episodic memories (McGaugh et al. 1996).

But is this always true? Might not there be a price to be paid for all this flexibility and parallel processing? In fact, there are reports of competitive interference between memory systems. For example, rats with fornix lesions disconnecting hippocampus from limbic regions learn to discriminate between two odor cues more quickly than controls, provided the task is configured to minimize comparisons between cues (Eichenbaum et al. 1988). Similarly, fornix lesions facilitate learning of a striataldependent win-stay radial maze task (Packard et al. 1989), and post-training inactivation of the hippocampus facilitates learning of a response-based water maze task (Schroeder et al. 2002). These findings, among others, have been interpreted as evidence of competition or interference between hippocampal and striatal memory systems. This notion of competition between memory systems makes perfect sense in these settings in which hippocampal-based strategies for learning a task may conflict with striatal-based strategies.

A new report by Stone and colleagues in this issue (Stone et al. 2005) offers another example of apparent competition between hippocampal and other memory systems, in this case in a setting in which there is no obvious reason for competition between the memory systems involved. Yet, as we argue below, these results may, in fact, shed light on one of the essential characteristics of the hippocampal contribution to memory.

These researchers examined the involvement of dorsal hippocampus in the acquisition of a conditioned taste aversion, a form of learning thought to depend on simple associative learning mechanisms, operating in areas such as amygdala and gustatory cortex. These researchers exposed rats to two different taste solutions-one new and one that the rats had experienced previously. After each exposure, the rats were made ill by injection of lithium chloride. After several of these taste-illness pairings, control rats consumed less of both flavored solutions, indicating a memory for the taste-illness associations. However, controls also drank more of the familiar than the novel solution. This difference, referred to as latent inhibition, shows that the rats also formed a memory of the prior exposure to the familiar taste and that this memory acted to counteract or hinder learning of the taste aversion.

\footnotetext{
'Corresponding author.

E-mail schoenbg@schoenbaumlab.org; fax (410) 706-2512.

Article and publication are at http://www.learnmem.org/cgi/doi/10.1101/ Im.115605.
}

Stone and colleagues found that inactivation of dorsal hippocampus, via muscimol injections, actually enhanced both types of learning. In other words, turning off hippocampus during the acquisition of the taste aversion caused the rats to show a greater aversion to the novel tastant during subsequent testing, while inactivation during pre-exposure to the familiar tastant caused the rats to show greater latent inhibition (less aversion) during subsequent testing. Although there is no obvious competition between hippocampal-based and amygdala-based strategies in this task, these effects show that processing in hippocampus somehow hinders efficient learning in this setting ... but how?

The answer can perhaps be understood from new conceptualizations of the role of the hippocampus in memory. Far from serving as the "memory" organ of the brain, the role played by hippocampus now appears to be far more specialized. Specifically, it has been proposed that hippocampus is critical for linking together bits of information so that they can be related, recalled, and applied flexibly and independently of the way they were originally learned (Eichenbaum 2000). This model has obvious power in explaining the spatial learning deficits that are found after hippocampal lesions; however, as Eichenbaum and colleagues have shown, this model also has predictive power in explaining deficits across a variety of other hippocampaldependent tasks. The model even suggests that hippocampal processing may allow rats to remember learning "episodes" by linking information with the time and context in which that information was learned. For example, in a recent article published in Nature, rats were taught to remember a series of odors that had been presented sequentially to them (Fortin et al. 2004). Eichenbaum and colleagues used a signal detection analysis of the rats' recognition performance to demonstrate that hippocampal lesions impaired precisely the part of their recognition performance that depended on recollection of specific learning episodes. These results suggest, in accord with the model, that hippocampal-lesioned rats are unable to tag new learning events with information concerning time and context. In other words, they are unable to form episodic memories.

Here this model can be used to explain the results in the experiment by Stone and colleagues. For example, an inability to separate learning by episodes-to allow recall of the specific context in which learning occurred-might enhance the expression of taste aversion learning during subsequent testing, because the rats would in effect overgeneralize their aversion and drink less solution when compared to control rats that had learned normally. Similarly, rats that failed to encode their experience with the familiar tastants during pre-exposure as a distinct episode might exhibit enhanced inhibition of learning during subsequent conditioning, because they would, in essence, be unable to distinguish the new conditioning sessions from the old pre-exposure sessions. These rats would thus drink more of the familiar tastants than controls in the final test session.

In each case, output from hippocampus would normally interfere with rapid and efficient new learning because it would contribute to the segregation of learning experiences into dis- 
tinct-and potentially different-episodes. This result thus provides striking new data showing that a relational account of hippocampal processing-one that incorporates time as a variable with which to create episodes-has predictive validity in describing hippocampal function.

\section{References}

Bechara, A., Tranel, D., Damasio, H., Adolphs, R., Rockland, C., and Damasio, A.R. 1995. Double dissociation of conditioning and declarative knowledge relative to the amygdala and hippocampus in humans. Science 269: 1115-1118.

Eichenbaum, H. 2000. A cortical-hippocampal system for declarative memory. Nat. Rev. Neurosci. 1: 41-50.

Eichenbaum, H., Fagan, A., Mathews, P., and Cohen, N.J. 1988. Hippocampal system dysfunction and odor discrimination learning in rats: Impairment or facilitation depending on representational demands. Behav. Neurosci. 102: 331-339.

Fortin, N.J., Wright, S.P., and Eichenbaum, H. 2004. Recollection-like memory retrieval in rats is dependent on the hippocampus. Nature 431: $188-191$.

McDonald, R.J. and White, N.M. 1993. A triple dissociation of memory systems: Hippocampus, amygdala, and dorsal striatum. Behav. Neurosci. 107: 3-22.

McGaugh, J.L., Cahill, L., and Roozendaal, B. 1996. Involvement of the amygdala in memory storage: Interaction with other brain systems. Proc. Natl. Acad. Sci. 93: 13508-13514.

Packard, M.G., Hirsh, R., and White, N.M. 1989. Differential effects of fornix and caudate nucleus lesions on two radial maze tasks: Evidence for multiple memory systems. J. Neurosci. 9: 1465-1472.

Schroeder, J.P., Wingard, J.C., and Packard, M.G. 2002. Post-training reversible inactivation of hippocampus reveals interference between memory systems. Hippocampus 12: 280-284.

Stone, M.E., Grimes, B.S., and Katz, D.B. 2005. Hippocampal inactivation enhances taste learning. Learn. Mem. (this issue). 


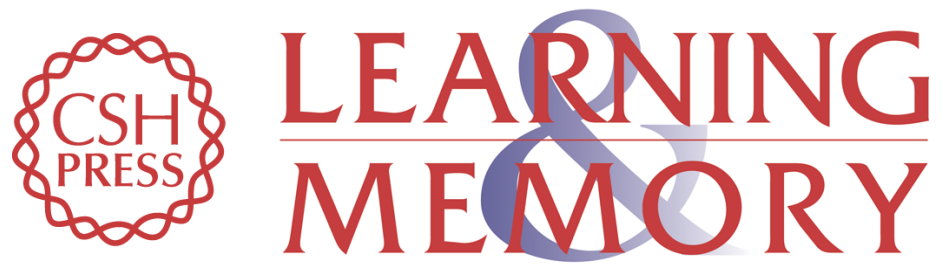

\section{Thanks for the memories...}

Geoffrey Schoenbaum and Thomas A. Stalnaker

Learn. Mem. 2005, 12:

Access the most recent version at doi:10.1101//m.115605

References This article cites 8 articles, 3 of which can be accessed free at: http://learnmem.cshlp.org/content/12/6/547.full.html\#ref-list-1

License

Email Alerting Receive free email alerts when new articles cite this article - sign up in the box at the Service top right corner of the article or click here. 